
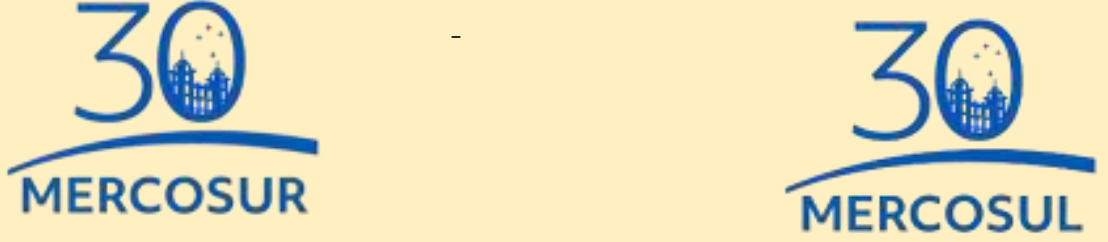

\title{
Aportes Académicos
}

$N^{\circ} 2$

Mayo 2021

Roberto Fonseca Feris

Víctor Carlos Fleitas Alvarez

\begin{tabular}{c|l}
++ & MERCOSUR \\
+ & $\begin{array}{l}\text { TPR } \\
\text { Tribunal Permanente } \\
\text { de Revisión }\end{array}$
\end{tabular}

Secretaría del Tribunal Permanente de Revisión 


\section{Aportes Académicos \\ $N^{\circ} 2$ \\ Mayo 2021}

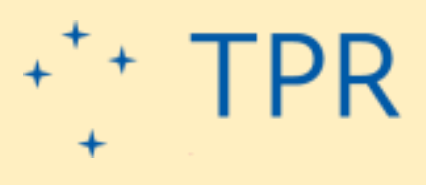

Secretaría del Tribunal Permanente de Revisión.

Centro Mercosur de Promoción de Estado de Derecho

www.tprmercosur.org

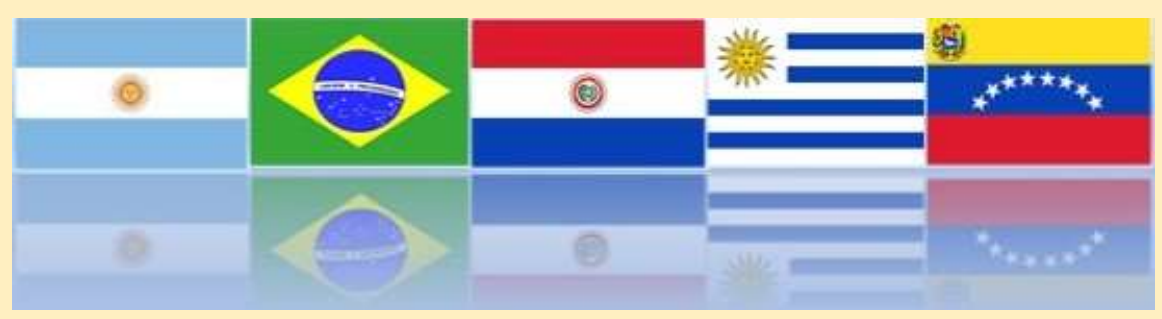




\section{Hito histórico en el Mercosur: Tribunal Permanente de \\ Revisión y el Laudo Arbitral n 1/2012 \\ http://dx.doi.org/10.1689o/aportes.n.2.2021}

\section{FICHA CATALOGRÁFICA}

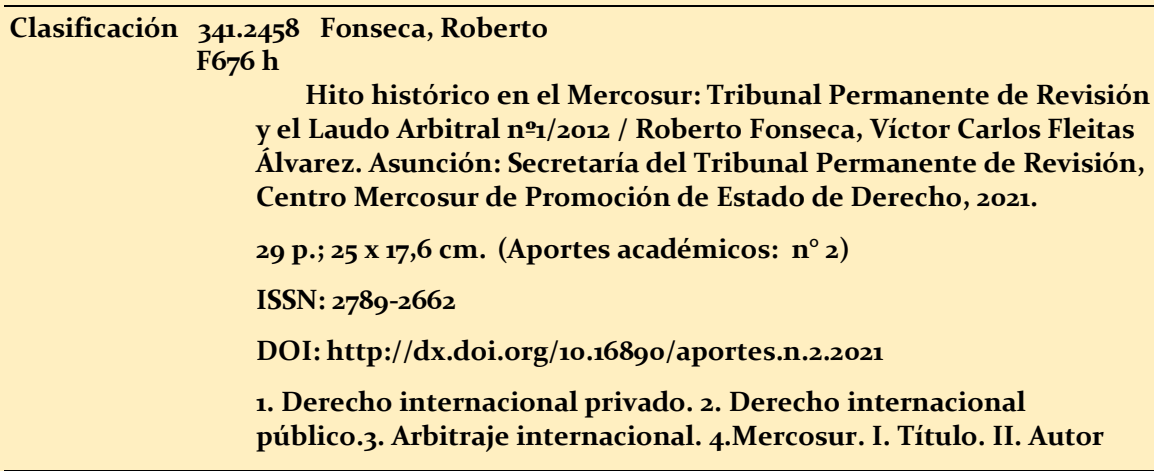

Bajo términos de licencia Creative commons 4.0

Secretaría del Tribunal Permanente de Revisión

Asunción, República del Paraguay, 2021

La reproducción total o parcial de esta publicación es autorizada siempre que se cite la fuente.

La información contenida en la publicación es responsabilidad exclusiva del autor/es de la misma. 
Hito histórico en el Mercosur: Tribunal Permanente de

Revisión y el Laudo Arbitral n 1/2012

http://dx.doi.org/10.1689o/aportes.n.2.2021

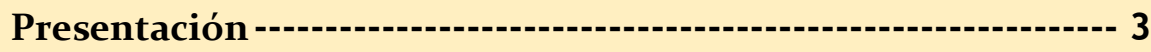

Hito histórico en el Mercosur: Tribunal Permanente de

Revisión y el laudo arbitral no 1/2012 ---------------------------- 5

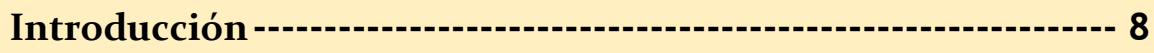

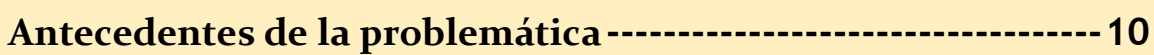

Sistema de solución de controversias en el Mercosur ---------14

Presentación de Paraguay de la controversia ante el TPR y

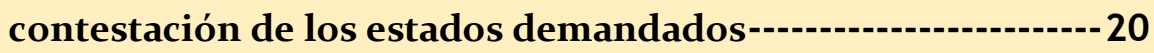

Proceso ante el Tribunal Permanente de Revisión--------------22

Análisis de la decisión del TPR a través del laudo arbitral no

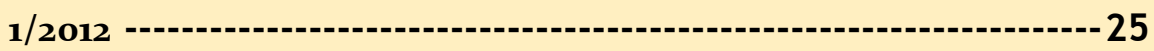

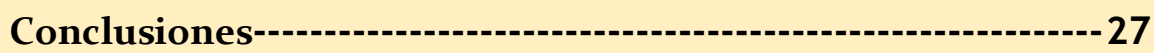

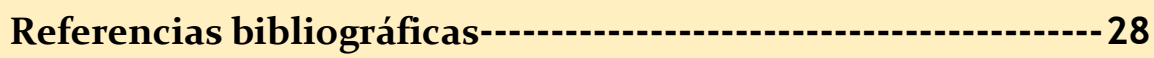




\section{Presentación}

Es una publicación digital editada por la Secretaría del Tribunal Permanente de Revisión, elaborada por el Centro Mercosur de Promoción de Estado de Derecho (CMPED) con la participación del área jurídica y la biblioteca institucional

Este espacio tiene la finalidad de divulgar trabajos académicos que por su estructura o contenido no cumplen requisitos determinados en la norma editorial para la publicación en la revista RSTPR, pero representan un aporte académico muy valioso y de alta calidad. El objetivo es difundir conocimientos generados por profesores, investigadores y operadores jurídicos a través de un trabajo inédito que contribuyen a la academia.

El segundo número de la serie presenta el trabajo de Roberto Fonseca Feris y Víctor Fleitas Álvarez quienes realizan un aporte inédito sobre el laudo $\mathrm{n}^{\circ}$ 1/2012 emitido por el TPR a solicitud de la República del Paraguay a través de una medida de urgencia, al ser afectado por la aplicación de la cláusula democrática del Mercosur establecida en el Protocolo de Ushuaia firmado el 24 de julio de 1998 lo que derivo a ser impedido de participar en las reuniones del bloque.

Los autores dan una visión jurídica sobre el tema, considerando que el laudo $\mathrm{n}^{\circ}$ 1/2012 el TPR demuestra que no solamente es un sistema de solución de controversias para dirimir cuestiones comerciales, sino que va más allá de lo que se pretende en la normativa vigente.

La Secretaría del Tribunal agradece a los autores de los aportes e invita a más profesionales del derecho y de la integración a contribuir con este espacio.

Dr. Juan Manuel Rivero Godoy

Secretario del Tribunal Permanente de Revisión 
Hito histórico en el Mercosur: Tribunal Permanente de Revisión y el Laudo Arbitral n 1/2012

http://dx.doi.org/10.1689o/aportes.n.2.2021

\section{Abreviaturas utilizadas}

CMC - Consejo del Mercado Común

GMC - Grupo Mercado Común

CCM- Comisión de Comercio del Mercosur

PO - Protocolo de Olivos para la solución de controversias en el Mercosur

PU - Protocolo de Ushuaia sobre compromiso democrático en el Mercosur, la República de Bolivia y la República de Chile

TA - Tratado de Asunción

TPR - Tribunal Permanente de Revisión 
Hito histórico en el Mercosur: Tribunal Permanente de Revisión y el Laudo Arbitral n 1/2012

http://dx.doi.org/10.1689o/aportes.n.2.2021

Hito histórico en el Mercosur: Tribunal Permanente de Revisión y el laudo arbitral $n^{\circ} 1 / 2012$

Marco histórico no Mercosul: Tribunal Permanente de Revisão e Sentença Arbitral no-1/2012

Historic milestone in Mercosur: Permanent Review Tribunal and Arbitration Award no1/2012

Jalon historique au Mercosur: Tribunal Permanent de Révision et sentence arbitrale no-1/2012.

Mgs. Roberto Fonseca Feris*1

Lic. Víctor Carlos Fleitas Alvarez*2

RESUMEN: La suspensión de Paraguay del sistema del Mercosur, que ocurrió en el año 2012, fue una decisión de los demás estados miembros del Mercosur por el incumplimiento de la llamada "cláusula democrática" aprobada en el Protocolo de Ushuaia. Ante esta situación, el Estado paraguayo sometió el asunto a consideración del Tribunal Permanente de Revisión. El TPR, cumplió los pasos formales establecidos y culminó su actuar dictando el laudo $n^{\circ} 1 / 2012$, sentando precedentes en la normativa del Mercosur, pues se

\footnotetext{
1 Magister en Derecho, Abogado, Docente Universidad Americana Paraguay. email: rfferis69@gmail.com

${ }^{2}$ Licenciado en Derecho por la Universidad Católica de Asunción, Abogado. email:

vicfleitas@hotmail.com
} 


\section{http://dx.doi.org/10.1689o/aportes.n.2.2021}

consideró competente no solo en controversias económicas sino también en las políticas. En esta investigación de tipo hermenéutica expositiva, se concluyó que la obligatoriedad de concurrencia de todos los requisitos previstos en el artículo 2 de la Decisión del Consejo de Mercado Común n ${ }^{\circ}$ 23/o7 para la procedencia de la medida excepcional de urgencia dejaría fuera asuntos de carácter comercial que cumpliesen solo con algunos de ellos, así como asuntos de otra índole que fuese necesario valorar con prontitud

RESUMO: A suspensão do Paraguai do sistema Mercosul, ocorrida em 2012, foi uma decisão dos demais Estados membros do Mercosul por descumprimento da chamada "cláusula democrática" aprovada no Protocolo de Ushuaia. Diante desta situação, o Estado paraguaio submeteu o assunto à consideração do Tribunal Permanente de Revisão. O TPR, cumpriu as etapas formais estabelecidas e culminou sua ação com a emissão do laudo nํ1/2012, abrindo precedentes na regulamentação do Mercosul, uma vez que foi considerado competente não só nas disputas econômicas, mas também na política. Nessa pesquisa expositiva de tipo hermenêutico, concluiu-se que a obrigatoriedade da concordância de todos os requisitos estabelecidos no art. 2º da Decisão do Conselho do Mercado Comúm № 23/o7 para a origem da medida emergencial excepcional deixaria de fora as questões comerciais que só atendiam a alguns dos eles, bem como assuntos de outra natureza que era necessário avaliar prontamente.

ABSTRACT: Paraguay's suspension from the Mercosur system, which occurred in 2012, was a decision of the other Mercosur member states for non-compliance with the so-called "democratic clause" approved in the Ushuaia Protocol. Faced with this situation, the Paraguayan State submitted the matter to the Permanent Review Court for consideration. The TPR, fulfilled the formal steps established and culminated its action by issuing the award 01/2012, setting precedents in the Mercosur regulations, since it was considered competent not only in economic disputes but also in politics. In this expository hermeneutic research, it was concluded that the mandatory concurrence of all the requirements set forth in article 2 of CMC 


\section{http://dx.doi.org/10.1689o/aportes.n.2.2021}

Decision №23/o7 for the origin of the exceptional emergency measure would leave out commercial matters that only complied with some of them, as well as other matters that need to be assessed promptly.

RÉSUMÉ: La suspension du Paraguay du système du Mercosur, intervenue en 2012, était une décision des autres États membres du Mercosur pour non-respect de la soi-disant «clause démocratique» approuvée dans le Protocole d'Ushuaia. Face à cette situation, l'État paraguayen a soumis la question à la Cour permanente de révision pour examen. Le TPR, a rempli les étapes formelles établies et a abouti

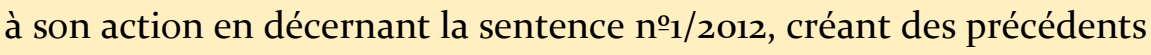
dans la réglementation du Mercosur, car il était considéré comme compétent non seulement dans les conflits économiques mais aussi en politique. Dans cette recherche herméneutique explicative, il a été conclu que la concordance obligatoire de toutes les exigences énoncées à l'article 2 de la décision CMC 23/07 pour l'origine de la mesure d'urgence exceptionnelle exclurait les questions commerciales qui ne respectaient que certaines ainsi que d'autres questions qui doivent être évaluées rapidement.

Palabras clave: Tribunal Permanente de Revisión, Laudo Arbitral 1/2012, Medidas excepcionales y de urgencias, Arbitraje internacional

Palavras-chave: Tribunal Permanente de Revisão, Laudo 1/2012, Medidas excepcionais e de urgência, Arbitragem internacional

Keywords: Permanent Review Tribunal, Arbitration Award 1/2012, exceptional emergency measures, International arbitration

Mots clés: Tribunal Permanent de Révision, sentence arbitrale 1/12, mesures d'urgence exceptionnelles, Arbitrage international 


\section{http://dx.doi.org/10.1689o/aportes.n.2.2021}

\section{Introducción}

El proceso de integración regional es clave para el desarrollo de los países en las circunstancias actuales donde priman fenómenos como la globalización, la transnacionalización y la internacionalización.

Para adaptarse al nuevo orden mundial, los Estados han creado bloques de integración que les permiten cooperar, progresar económicamente, y protegerse económica y políticamente.

Bajo ese concepto se concertó la creación del Mercosur en el año 1991 a través del Tratado de Asunción (TA), documento constitutivo y base de las relaciones entre los Estados fundadores entre los que se encontraban la República de Argentina, la República Federativa de Brasil, la República de Paraguay y la República Oriental de Uruguay.

El propósito fundamental de este sistema regional es constituir un Mercado Común, que consiste en la libre circulación de bienes, productos y servicios, eliminar derechos aduaneros y restricciones no arancelarias a la circulación de mercadería, tal y como se establece en el artículo 1 del TA.

Toda integración económica lleva implícita una integración política; por esta razón en el año 1998, se firma por los Estados Partes, el Protocolo de Ushuaia (PU), a través del cual se incluye un aspecto político al Tratado de Asunción y es la "cláusula democrática" considerando que la plena vigencia de las instituciones democráticas, en los países miembros, es fundamental para el desarrollo del Mercado Común del Sur.

Esta cláusula se utilizó por primera vez en el año 2012 a la República de Paraguay, en la Cumbre de Presidentes del Mercosur realizada en Mendoza, al considerar los demás Estados miembros que se habían violentado principios del debido proceso al juicio político 
Hito histórico en el Mercosur: Tribunal Permanente de

Revisión y el Laudo Arbitral n 1/2012

\section{http://dx.doi.org/10.1689o/aportes.n.2.2021}

realizado al presidente en aquel entonces Fernando Lugo; lo que afectaba la democracia en el país.

Como resultado se suspendió a Paraguay del sistema del Mercosur hasta que se restaurara un sistema democrático, que se traduce en la elección de un presidente por el pueblo, cumpliendo los requisitos de un gobierno democrático.

Paraguay, no estuvo conforme con la decisión, en tal sentido promovió una reclamación ante el Tribunal Permanente de Revisión (TPR).

El propósito fundamental perseguido en este artículo es analizar el Laudo nำ1/2012 del TPR, donde se resuelve la litis sometida al órgano judicial.

En tal sentido se plantea como objetivo general el siguiente:

Analizar la procedencia de del Laudo Arbitral n¹/2012 dictado por el Tribunal Permanente de Revisión.

Y como objetivos específicos:

a) Identificar el cumplimiento de los aspectos formales en el Laudo Arbitral 1/2012 dictado por el TPR

b) Resumir los principales aspectos de fondo resueltos por el TPR mediante el Laudo Arbitral o1/2012.

c) Valorar la interpretación del artículo 23 del Protocolo de los Olivos, realizada por el Tribunal arbitral en el laudo $1 / 2012$.

d) Valorar la interpretación del artículo 2 de la Decisión del Consejo del Mercado Común n 23/2004 realizada

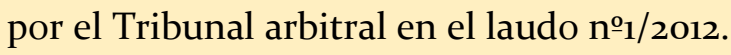

Posee conveniencia este artículo ya que al analizar las leyes vigentes en el Mercosur como consecuencia de la interpretación por el TPR de las Decisiones del CMC, se ofrecen pautas de los pasos para las soluciones de controversias futuras dentro del eje regional. 


\section{http://dx.doi.org/10.1689o/aportes.n.2.2021}

Serán beneficiados con la misma los juristas estudiosos de diferentes materias como Derecho Internacional, Derecho a la Integración de los Pueblos, y puede servir de sustento a trabajos relacionados con la solución de conflictos en el marco del TPR.

La presente exposición es de tipo jurídico doctrinal, específicamente hermenéutica expositiva.

Las fuentes de investigación utilizadas fueron primarias, dadas en primer lugar por el análisis del laudo arbitral 1/2012 dictado por el TPR, así como normas que rigen la actividad del Mercosur; y secundarias, relacionadas con obras de otros autores consultadas.

\section{Antecedentes de la problemática}

En fecha 29 de junio de 2012, en la Cumbre de los Jefes de Estados del Mercosur, en la ciudad de Mendoza, Argentina, se decidió la suspensión de Paraguay del derecho de participar en los órganos del Mercosur y de las deliberaciones, en los términos del artículo $5^{\circ}$ del Protocolo de Ushuaia.

La decisión tiene como fundamento la ruptura del orden democrático en la República de Paraguay, por la realización del juicio político al presidente en aquel entonces Fernando Lugo, al considerar el Mercosur un irrespeto por el gobierno paraguayo del "debido proceso" en la conservación del orden democrático.

El juicio político se encuentra establecido en la Constitución democrática de Paraguay adoptada el 20 de junio de 2002, donde se dispone que "el Presidente de la República (...) solo podrán ser sometidos a juicio político por mal desempeño de sus funciones, por delitos cometidos en el ejercicio de sus cargos o por delitos comunes"; más delante se plantea que "la acusación será formulada por la Cámara de Diputados, por mayoría de dos tercios. Corresponderá a la Cámara de Senadores, por mayoría absoluta de dos tercios, juzgar en 


\section{http://dx.doi.org/10.1689o/aportes.n.2.2021}

juicio público a los acusados por la Cámara de Diputados y en su caso, declararlos culpables, al solo efecto de separarlos de su cargo.

En esta dirección Forno plantea:

Si bien es cierto el pronunciamiento de las cámaras parlamentaras respecto de la legalidad o ilegalidad de los funcionarios se limita a una suerte de precalificación que, de encontrar indicios razonables de comisión de delito, se limita a trasladar el juzgamiento, propiamente dicho, a la administración de justicia; no es menos cierto que, en el ejercicio de las mismas atribuciones constitucionales, los parlamentos tienen un poder sancionador.

Es justamente por la posibilidad del ejercicio del poder sancionador en sede parlamentaria, que los procedimientos desarrollados para ello deben estar organizados de manera que se cumpla con las reglas mínimas del debido proceso que permita a los funcionarios imputados defenderse de las acusaciones de las que son sujeto. ${ }^{3}$

El procedimiento que se regula para el juicio político que se realiza en sede parlamentaria, necesita cumplir con formalidades y requisitos, razón por la cual debe ser justo, transparente y rápido; pero la rapidez no puede ir en contra del debido proceso, ya que deben cumplirse los principios elementales del mismo, como el de legalidad, juez natural, presunción de inocencia, derecho a la comunicación previa y detallada de la acusación, derecho a tiempo y medios adecuados para la defensa, derecho a un plazo razonable en la investigación y proceso.

Según Estragó, el procedimiento implementado para el juicio político, carece de legalidad y legitimidad constitucionales y fractura la carta magna, al reglamentarla sin

\footnotetext{
${ }^{3}$ FORNO, Giovani, "Juicio político y debido proceso en Latinoamérica", Cuadernos Manuel Giménez, Perú, https://dialnet.unirioja.es/servlet/articulo?codigo=434776o,p.136
} 


\section{Hito histórico en el Mercosur: Tribunal Permanente de Revisión y el Laudo Arbitral n 1/2012 \\ http://dx.doi.org/10.1689o/aportes.n.2.2021}

fuerza de ley. Así ocurre, porque tal reglamento, no puede constituirse en parte de nuestro ordenamiento jurídico, al no ser sancionado y promulgado como ley. La facultad que tiene el Parlamento de dictar su propio reglamento, solo importa al funcionamiento de ambas cámaras y a la plenaria de la bicameral. Pero, nunca puede servir como instrumento legal y valido al instalarse la Cámara de Senadores, como Tribunal de Juicio Político. ${ }^{4}$

$\mathrm{Al}$ realizar un análisis del procedimiento seguido contra el ex presidente Fernando Lugo, varios países y organizaciones internacionales mostraron su preocupación ya que no existía al momento del juicio político, un reglamento que dispusiera los pasos a seguir para su realización, por este motivo consideraron no se habían cumplido todos los requisitos del debido proceso, principalmente el derecho a la defensa, lo que podía desencadenar una ola de violencia interna en el país.

El Mercosur hizo sus consideraciones y determinó también que la ausencia de un procedimiento previo y la forma en que se llevó a cabo el juicio político, violaba lo dispuesto en el Protocolo de Ushuaia, firmado por los países miembros de esta comunidad en el mes de julio del año 2010.

La infracción que de forma unánime plantearon los restantes países miembros fundadores del Mercosur estaba dada por el incumplimiento de la "cláusula democrática", incluida al sistema como matiz político imprescindible para llevar a efectos la integración económica, tal y como se regula en el artículo 1 del PU, "la plena vigencia de las instituciones democráticas es condición esencial para el desarrollo de los procesos de integración entre los Estados Partes del presente Protocolo"

\footnotetext{
4 ESTRAGÓ, Gloria, "Por qué es ilegal e ilegítimo el juicio político a Fernando Lugo",
} https://es.scribd.com/document/101031707/. 


\section{Hito histórico en el Mercosur: Tribunal Permanente de Revisión y el Laudo Arbitral n 1/2012 \\ http://dx.doi.org/10.1689o/aportes.n.2.2021}

De igual forma en el PU se reflejan los requisitos de aplicación de la cláusula, los cuales aparecen cuando se afecte el orden democrático, como ya se ha planteado; "este Protocolo se aplicará a las relaciones que resulten de los respectivos Acuerdos de integración vigentes entre los Estados partes del presente Protocolo, en caso de ruptura del orden democrático en alguno de ellos". (Art 2 PU)

Pero no solo queda reflejada en el PU, la "cláusula democrática", sino que se incluye como parte integrante del TA, tal y como se regula en el artículo 8 del PU. 5

Así se introdujo una novedad al TA, pues esta cláusula de orden político, desde el punto de vista de la jerarquía jurídica del Mercosur, se corresponde a un derecho originario, atípico y sui géneris en correspondencia con lo regulado en el artículo $41 \mathrm{del}$ Protocolo de Ouro Preto.

Sobre este aspecto Deluca, refiere

Así pues, nos encontramos frente a una norma de carácter originario -no ya comercial, sino de índole política- que modifica sensiblemente los análisis y previsiones legales vigentes hasta el momento.

Esta situación permite afirmar que -en última instanciasi bien el PU nace como un Protocolo Adicional al TA, ha mutado para introducir en el núcleo duro -constitutivo- del Mercosur una condición de carácter eminentemente político. ${ }^{6}$

Como consecuencia de la decisión de suspender a Paraguay por incumplimiento de la cláusula democrática prevista en el PU perdió de forma inmediata los derechos de participar en los órganos de administración y los demás foros

\footnotetext{
5 Artículo 8 Protocolo Ushuaia: El presente Protocolo es parte integrante del Tratado de Asunción y de los respectivos Acuerdos de integración celebrados entre el Mercosur y la República del Bolivia y el Mercosur y la República de Chile.

6 DELUCA, Santiago, "El Mercosur tras la suspensión de Paraguay y el ingreso de Venezuela: Ponderación del Laudo TPR n ${ }^{\circ}$ 1/2012", p.13.
} 


\section{Hito histórico en el Mercosur: Tribunal Permanente de Revisión y el Laudo Arbitral n 1/2012 \\ http://dx.doi.org/10.1689o/aportes.n.2.2021}

del Mercosur, según lo previsto en el artículo 5, segundo párrafo del citado instrumento jurídico. ${ }^{7}$

El Estado de Paraguay, ante tal decisión optó por establecer un procedimiento ante el Tribunal Permanente de Revisión.

\section{Sistema de solución de controversias en el Mercosur}

Resulta necesario, antes de analizar el procedimiento iniciado por Paraguay, hacer alusión al Sistema de Solución de Controversias que rige en el Mercosur, y cuál es su base jurídica.

Obligatoriamente se debe partir del Tratado de Asunción, quien dio origen al Mercosur, el mismo regula en el Anexo III los aspectos referidos a la solución de controversias, las cuales se resolverán mediante negociaciones directas, y en caso que no se llegar a acuerdo se someterán al Grupo Mercado Común quienes dictarán recomendaciones; en caso que a través del GMC no se llegue a un acuerdo, los Estados partes llevarán la controversia al Consejo Mercado Común, órgano superior del Mercosur, quien emitirá también recomendaciones.

Puede apreciarse que ambos órganos no adoptan decisiones, sino recomendaciones, las cuales no son vinculatorias para los Estados. ${ }^{8}$ Tal análisis corresponde a que el proceso de solución de

\footnotetext{
7 Artículo 5 Protocolo Ushuaia: Dichas medidas abarcarán desde la suspensión del derecho a participar en los distintos órganos de los respectivos procesos de integración, hasta la suspensión de los derechos y obligaciones emergentes de esos procesos.

${ }^{8}$ Anexo III. Solución de Controversias: 1 . Las controversias que pudieren surgir entre los Estados Partes como consecuencia de la aplicación del Tratado serán resueltas mediante negociaciones directas. En caso de no lograr una solución dichos Estados Partes someterán la controversia a consideración del Grupo Mercado Común, el que luego de evaluar la situación formulará en el lapso de sesenta (6o) días las recomendaciones pertinentes a las Partes para la solución del diferendo. A tal efecto, el Grupo Mercado Común podrá establecer o convocar paneles de
} 


\section{Hito histórico en el Mercosur: Tribunal Permanente de Revisión y el Laudo Arbitral n 1/2012 \\ http://dx.doi.org/10.1689o/aportes.n.2.2021}

controversias que se observa en el Tratado es provisional, pues se prevé más adelante la creación de un sistema permanente para la solución de los conflictos entre los Estados. ${ }^{9}$

De igual forma, siguiendo el espíritu del TA, las controversias que se someten al GMC y CMC, son comerciales pues el propósito del TA, es constituir un Mercado Común.

$\mathrm{Al} \mathrm{TA}$, le sigue como norma para la solución de controversias el Protocolo de Brasilia, el cual se firmó en diciembre de 1991; tiene como propósito regular la intervención cuando exista disparidad entre las normas del TA, sus acuerdos y las decisiones del CMC. ${ }^{10}$

Parte del mismo principio que cuando dos Estados miembros se encuentran en conflicto deben primeramente recurrir a las negociaciones directas, si no existe acuerdo pueden someter el asunto al GMC quien emite recomendaciones y si estas no son cumplidas o aceptadas por las partes se someten a un nuevo órgano que se crea a través del PB, que es el Tribunal Arbitral Ad hoc, quien dicta sus decisiones a través de un laudo arbitral."

En esta regulación se observa cómo se mantienen las negociaciones directas como paso previo a la participación de los

expertos o grupos de peritos con el objeto de contar con asesoramiento técnico. Si en el ámbito del Grupo Mercado Común tampoco se alcanza una solución, se elevará la controversia al Consejo Mercado Común, para que adopte las recomendaciones pertinentes.

9 2. Dentro de los ciento veinte (120) días de la entrada en vigor del Tratado, el Grupo Mercado Común elevará a los Gobiernos de los Estados Partes una propuesta de Sistema de Solución de Controversias que regirá durante el período de transición. 3. Antes del 31 de diciembre de 1994, los Estados Partes adoptarán un Sistema Permanente de Solución de Controversias para el Mercado Común.

1o Artículo 1 Protocolo Brasilia: Las controversias que surjan entre los Estados Partes sobre la interpretación, aplicación o incumplimiento de las disposiciones contenidas en el Tratado de Asunción, de los acuerdos celebrados en el marco del mismo, así como de las decisiones del Consejo del Mercado Común y de las resoluciones del Grupo Mercado Común, serán sometidas a los procedimientos de solución establecidos en el presente Protocolo.

"Artículo 7 Protocolo de Brasilia: 1. Cuando la controversia no hubiera podido solucionarse mediante la aplicación de los procedimientos referidos en los capítulos II y III, cualquiera de los Estados Partes en la controversia podrá comunicar a la Secretaría Administrativa su intención de recurrir al procedimiento arbitral que se establece en el presente Protocolo 


\section{Hito histórico en el Mercosur: Tribunal Permanente de Revisión y el Laudo Arbitral n 1/2012 \\ http://dx.doi.org/10.1689o/aportes.n.2.2021}

órganos del Mercosur, y solo si no existen acuerdos, se somete el asunto a la consideración de estos.

Se mantiene que el GMC dicta recomendaciones que no son de obligatorio cumplimiento; pero ya el Tribunal Arbitral Ad hoc dicta un laudo arbitral, que si es de obligatorio cumplimiento para las partes; y en caso de no cumplirse se le da la potestad a la parte afectada para que adopte medidas compensatorias. ${ }^{12}$

Analizando el espíritu de esta norma se observa que mantiene el mismo carácter comercial de las controversias presentadas.

En diciembre del año 1994 se firma por los Estados partes el Protocolo de Ouro Preto, mediante el cual se regula la estructura orgánica del Mercosur y con relación a la solución de controversias remite el Protocolo de Brasilia; y se esboza la necesidad de conformar un sistema permanente para la solución de los conflictos. ${ }^{13}$

Este sistema permanente sale a la luz en el año 2002, con la firma del Protocolo de los Olivos.

El procedimiento en este protocolo parte de los elementos fundamentales de sus antecesores, o sea, las negociaciones directas entre los Estados partes, al no llegar a acuerdo se puede someter la controversia al GMC, quien emite recomendaciones, o directamente se puede presentar por la parte que se considera afectada al

\footnotetext{
${ }^{12}$ Artículo 21 Protocolo de Brasilia: 1. Los laudos del Tribunal Arbitral son inapelables, obligatorios para los Estados partes en la controversia a partir de la recepción de la respectiva notificación y tendrán respecto de ello fuerza de cosa juzgada.

13 Artículo 43 del Protocolo de Ouro Preto: Las controversias que surgieran entre los Estados Partes sobre la interpretación, aplicación o incumplimiento de las disposiciones contenidas en el Tratado de Asunción, de los acuerdos celebrados en el marco del mismo, así como de las Decisiones del Consejo del Mercado Común, de las Resoluciones del Grupo Mercado Común y de las Directivas de la Comisión de Comercio del Mercosur, serán sometidas a los procedimientos de solución establecidos en el Protocolo de Brasilia, del 17 de diciembre de 1991. Artículo 44. Antes de culminar el proceso de convergencia del Arancel Externo Común, los Estados Partes efectuarán una revisión del actual sistema de solución de controversias del Mercosur con miras a la adopción del sistema permanente a que se refieren el ítem 3 del Anexo III del Tratado de Asunción, y el artículo 34 del Protocolo de Brasilia.
} 


\title{
Hito histórico en el Mercosur: Tribunal Permanente de Revisión y el Laudo Arbitral n 1/2012 \\ http://dx.doi.org/10.1689o/aportes.n.2.2021
}

\author{
Procedimiento Arbitral, conformando un Tribunal Arbitral Ad hoc, \\ quien dicta el laudo arbitral. ${ }^{14}$
}

La novedad del PO, es que crea el Tribunal Permanente de Revisión, quien tiene la función de resolver los casos que se le sometan a su consideración por la parte inconforme con el laudo del TA Ad hoc, siempre que la inconformidad esté relacionada con cuestiones de derecho y no de hecho. ${ }^{15}$

También resulta novedosa la regulación en el artículo 24 de PO, en el sentido que deja expedita la posibilidad al GMC para atender casos excepcionales que pudieran ocasionar daños irreparables a las partes. ${ }^{16}$

El TPR, resuelve a través de un laudo y puede confirmar, modificar o revocarla decisión del Tribunal Arbitral Ad hoc.

\section{Otra particularidad del PO es que deroga el Protocolo de} Brasilia. $^{17}$

\footnotetext{
${ }_{14}$ Protocolo de los Olivos Artículo 4: Los Estados partes en una controversia procurarán resolverla, ante todo, mediante negociaciones directas. Artículo 6. 1. Si mediante las negociaciones directas no se alcanzare un acuerdo o si la controversia fuere solucionada solo parcialmente, cualquiera de los Estados partes en la controversia podrá iniciar directamente el procedimiento arbitral previsto en el Capítulo VI. Artículo 16. El Tribunal Arbitral Ad Hoc dictará el laudo en un plazo de sesenta (6o) días, prorrogables por decisión del Tribunal por un plazo máximo de treinta (30) días, contado a partir de la comunicación efectuada por la Secretaría Administrativa del Mercosur a las partes y a los demás árbitros, informando la aceptación por el árbitro Presidente de su designación.

15 Protocolo de los Olivos Artículo 17. 1. Cualquiera de las partes en la controversia podrá presentar un recurso de revisión al Tribunal Permanente de Revisión, contra el laudo del Tribunal Arbitral Ad Hoc en un plazo no superior a quince (15) días a partir de la notificación del mismo.

${ }^{16}$ Protocolo de los Olivos Artículo 24. El Consejo del Mercado Común podrá establecer procedimientos especiales para atender casos excepcionales de urgencia, que pudieran ocasionar daños irreparables a las Partes.

${ }^{17}$ Protocolo de los Olivos Artículo 55: El presente Protocolo deroga, a partir de su entrada en vigencia, el Protocolo de Brasilia para la Solución de Controversias, suscripto el 17 de diciembre de 1991 y deroga el Reglamento del Protocolo de Brasilia, Decisión CMC nº 17/98.
} 
Hito histórico en el Mercosur: Tribunal Permanente de Revisión y el Laudo Arbitral n 1/2012

\section{http://dx.doi.org/10.1689o/aportes.n.2.2021}

En tal sentido las decisiones del TA Ad hoc y del TPR son de obligatorio cumplimiento por las partes, el no cumplimiento del laudo del TPR mantiene la posibilidad al afectado que se apliquen medidas compensatorias; y el espíritu de los asuntos sometidos a su consideración continúa siendo de carácter comercial. ${ }^{18}$

Deluca, plantea que existen una serie de características que, a la par de contar con la aceptación prácticamente unánime de la doctrina, también pueden observarse como reflejos del Sistema de Solución de Controversias mismo: flexibilidad, celeridad y obligatoriedad.

Flexibilidad, ya que se prevén diversas modalidades a las que podrán recurrir las partes, según la naturaleza de la controversia. Celeridad, en virtud del carácter comercial que tendrá la mayoría de los casos que se inicien, los plazos previstos son breves y los procedimientos relativamente sencillos.

Obligatoriedad, derivado del entendimiento de que el recurso arbitral asegura un resultado de cumplimiento compulsivo para las partes en la controversia.

En definitiva, puede afirmarse sin temor a yerros que el actual sistema de solución de controversias del Mercosur responde a la característica de intergubernamentalidad.

Es decir, no registra delegación de competencias correspondientes a los poderes de los Estados Parte -ejecutivo, legislativo y judicial. ${ }^{19}$

\footnotetext{
${ }^{18}$ Protocolo de los Olivos, Artículo 26: 1. Los laudos de los Tribunales Arbitrales Ad Hoc son obligatorios para los Estados partes en la controversia a partir de su notificación y tendrán, con relación a ellos, fuerza de cosa juzgada si transcurrido el plazo previsto en el Artículo 17.1 para interponer el recurso de revisión, éste no fuere interpuesto. 2. Los laudos del Tribunal Permanente de Revisión son inapelables, obligatorios para los Estados partes en la controversia a partir de su notificación y tendrán, con relación a ellos, fuerza de cosa juzgada. Artículo 27. Los laudos deberán ser cumplidos en la forma y con el alcance con que fueron dictados. La adopción de medidas compensatorias en los términos de este Protocolo no exime al Estado parte de su obligación de cumplir el Laudo.
}

${ }^{19}$ DELUCA, Santiago, Ob. cit., p.12. 


\section{Hito histórico en el Mercosur: Tribunal Permanente de Revisión y el Laudo Arbitral n 1/2012 \\ http://dx.doi.org/10.1689o/aportes.n.2.2021}

Luego prosigue:

No se trata de un mecanismo de tinte judicial tradicional como el que se vislumbra en sus Estados Parte, o como el de los modelos de la Unión Europea, la Comunidad Andina o la Corte Interamericana de Derechos Humanos. Por tanto, es dable sostener que el sistema escogido por el Mercosur es pura y exclusivamente de tinte arbitral mixto, coexistiendo tipologías ad hoc e institucionales y registrando algunos matices diferenciales que a simple vista resultan ajenos a este tipo de sistemas -ej. facultades revisoras y consultivas-. ${ }^{20}$

Teniendo en cuenta la regulación del artículo 24 del PO, el Consejo del Mercado Común aprobó la Decisión, MERCOSUR/CMC/DEC. N. 23/04, con el propósito de regular la solución de controversias en casos excepcionales o de urgencia y establece que:

Art. 2 - Cualquier Estado Parte podrá recurrir ante el Tribunal Permanente de Revisión bajo el procedimiento establecido en la presente Decisión siempre que se cumplan los siguientes requisitos: a.- que se trate de bienes perecederos, estacionales, o que por su naturaleza y características propias perdieran sus propiedades, utilidad y/o valor comercial en un breve período de tiempo, si fueran retenidos injustificadamente en el territorio del país reclamado; o de bienes que estuviesen destinados a atender demandas originadas en situaciones de crisis en el Estado Parte importador; b.- que la situación se origine en acciones o medidas adoptadas por un Estado Parte, en violación o incumplimiento de la normativa Mercosur vigente; c.-que el mantenimiento de esas acciones o medidas puedan producir daños graves e irreparables; d.- que las acciones o medidas cuestionadas no estén siendo objeto de una controversia en curso entre las partes involucradas.

20 DELUCA, Santiago, Ob.cit., p. 19. 


\section{http://dx.doi.org/10.1689o/aportes.n.2.2021}

Estas medidas están estrechamente vinculadas con la actividad mercantil, pues expone de forma expresa "bienes perecederos que puedan perder sus propiedades o valor comercial”.

No obstante, no se define expresamente si deben estar presentes todos los requisitos para ofrecer la medida de urgencia o solo algunos de ellos.

\section{Presentación de Paraguay de la controversia ante el TPR y contestación de los estados demandados}

La controversia presentada por Paraguay estuvo centrada en dos aspectos fundamentales; el primero la suspensión del sistema del Mercosur y la segunda la aceptación de Venezuela como país miembro, sin que estuviese presente el Estado Paraguayo, quien se había opuesto antes a la admisión en el bloque.

A los efectos de este artículo se analiza solo el primer aspecto, o sea, la suspensión de Paraguay del Mercosur.

La demanda presentada, solicita que se aplique una medida excepcional de urgencia, teniendo en cuenta lo establecido en el artículo 24 del Protocolo de los Olivos, donde se expone: "El Consejo del Mercado Común podrá establecer procedimientos especiales para atender casos excepcionales de urgencia, que pudieran ocasionar daños irreparables a las Partes".

El procedimiento para estas medidas excepcionales o de urgencia se encuentra recogido en la ya mencionada MERCOSUR/CMC/DEC. N. $23 / 04$.

De forma subsidiaria alega el artículo 1 del Protocolo de los Olivos el que expresa "Las controversias que surjan entre los Estados Partes sobre la interpretación, aplicación o incumplimiento del Tratado de Asunción, del Protocolo de Ouro Preto, de los protocolos y acuerdos celebrados en el marco del Tratado de Asunción, de las 


\section{http://dx.doi.org/10.1689o/aportes.n.2.2021}

Decisiones del Consejo del Mercado Común, de las Resoluciones del Grupo Mercado Común y de las Directivas de la Comisión de Comercio del Mercosur, serán sometidas a los procedimientos establecidos en el presente Protocolo".

Sobre las cuestiones de fondo expuso la reclamación que con la decisión de suspenderlo del Mercosur se afectaba a Paraguay como Estado fundador, y le impedían ejercer derechos soberanos e inalienables que posee por su condición; planteando que el juicio político en nada alteró el orden democrático que existía en el país.

Lo anterior se incluyó, según se puede apreciar con el propósito de fundamentar desde el punto de vista jurídico su acceso directo ante el TPR.

Por su parte, los Estados demandados Argentina, Brasil y Uruguay, expusieron cuestiones previas relacionadas con la competencia del TPR, alegando que las medidas de urgencia previstas en la MERCOSUR/CMC/DEC. N.o 23/o4, eran solo para actos relacionados con la actividad comercial; y por la otra que no se había cumplido lo previsto en el artículo 23 del PO para acceder directamente al TPR, ya que Paraguay no había cumplido con el trámite de las negociaciones previas, ni siquiera intentó realizar las mismas con los Estados que ahora demanda.

Sobre las cuestiones de fondo fundamentaron que sí existía violación de la "cláusula democrática" incorporada al TA a través del PU y que es de máxima trascendencia para la integración de los pueblos que se cumpla con la misma ya que se realizó el juicio político violando garantías del debido proceso, las que deben estar presentes en todas las disciplinas jurídicas.

Plantean que la medida es de carácter provisorio, hasta que se restablezca el orden democrático en el país.

Desde la óptica del procedimiento se puede apreciar que cada parte nombró sus representantes, expuso sus alegaciones dentro de 
Hito histórico en el Mercosur: Tribunal Permanente de Revisión y el Laudo Arbitral n 1/2012

http://dx.doi.org/10.1689o/aportes.n.2.2021

los plazos previstos, ofreciendo las pruebas que consideraba procedentes para demostrar su dicho.

\section{Proceso ante el Tribunal Permanente de Revisión}

El TPR, en su laudo analiza no solo lo que está expresamente normado, sino aquello que se interpreta de las disposiciones legales existentes.

Parte que la regulación legal del Mercosur aún está en constante perfeccionamiento y evolución, no es algo acabado y por ello se nutre de los nuevos sucesos que ocurren. De tal suerte analiza que se deben interpretar esas regulaciones de forma justa para lograr un equilibrio dentro del sistema legal.

Plantean que si bien en cierto no se encuentra expresamente regulado un procedimiento para conocer las controversias por asuntos "políticos" que ocurran entre los Estados; esto no significa que no puedan conocer de estas controversias, por lo que realizan una interpretación tanto del TA como del PO, y también del preámbulo del PU (que no obliga, pero traza pautas). ${ }^{21}$

Como consecuencia de este análisis determina que sí son competentes para conocer de los asuntos que en materia política surjan entre los Estados partes.

Lo expuesto crea un precedente, nunca antes analizado en este sistema de solución de conflictos, que se centraba solamente en el orden económico, razón principal del Mercosur, antes de acordar el PU.

\footnotetext{
${ }^{21}$ RECONOCIENDO: Que la evolución del proceso de integración en el ámbito del Mercosur requiere del perfeccionamiento del sistema de solución de controversias; CONSIDERANDO La necesidad de garantizar la correcta interpretación, aplicación y cumplimiento de los instrumentos fundamentales del proceso de integración y del conjunto normativo del Mercosur, de forma consistente y sistemática.
} 


\title{
Hito histórico en el Mercosur: Tribunal Permanente de Revisión y el Laudo Arbitral n 1/2012 \\ http://dx.doi.org/10.1689o/aportes.n.2.2021
}

Significa que, por cuestiones políticas derivadas del PU, se pueden someter asuntos al TPR, quien tiene la obligación de analizar, luego de verificar el cumplimiento de los pasos previsto para su presentación.

En otro orden, hace un análisis del procedimiento para conocer las medidas excepcionales de urgencia ${ }^{22}$; y en este aspecto valora, siguiendo el texto de la decisión MERCOSUR/CMC/DEC. $\mathrm{n}^{\circ}$ 23/04, que esos requisitos son acumulativos y no deben interpretarse de forma separada, ${ }^{23}$ concluyendo que solo puede establecerse este procedimiento para medidas excepcionales cuando se trate de asuntos comerciales, dejando así fuera de las competencias del TPR las medidas de urgencia por cuestiones políticas previstas en el PU.

\author{
El tercer aspecto del laudo dictado por el TPR, se relaciona con \\ el acceso directo previsto en el artículo 1 y 23 del PO. ${ }^{24}$
}

\footnotetext{
${ }^{22}$ Decisión 23/04: Art. 1 - Establecer el procedimiento para atender los casos excepcionales de urgencia, a que hace referencia el artículo 24 del Protocolo de Olivos para la Solución de Controversias en el Mercosur.
}

\begin{abstract}
${ }^{23}$ Art. 2 - Cualquier Estado Parte podrá recurrir ante el Tribunal Permanente de Revisión (TPR) bajo el procedimiento establecido en la presente Decisión siempre que se cumplan los siguientes requisitos: a.- que se trate de bienes perecederos, estacionales, o que por su naturaleza y características propias perdieran sus propiedades, utilidad y/o valor comercial en un breve período de tiempo, si fueran retenidos injustificadamente en el territorio del país reclamado; o de bienes que estuviesen destinados a atender demandas originadas en situaciones de crisis en el Estado Parte importador; b.- que la situación se origine en acciones o medidas adoptadas por un Estado Parte, en violación o incumplimiento de la normativa Mercosur vigente; c.-que el mantenimiento de esas acciones o medidas puedan producir daños graves e irreparables; d.que las acciones o medidas cuestionadas no estén siendo objeto de una controversia en curso entre las partes involucradas.
\end{abstract}

${ }^{24}$ Protocolo de los Olivos. Artículo 1.1 Las controversias que surjan entre los Estados Partes sobre la interpretación, aplicación o incumplimiento del Tratado de Asunción, del Protocolo de Ouro Preto, de los protocolos y acuerdos celebrados en el marco del Tratado de Asunción, de las Decisiones del Consejo del Mercado Común, de las Resoluciones del Grupo Mercado Común y de las Directivas de la Comisión de Comercio del Mercosur, serán sometidas a los procedimientos establecidos en el presente Protocolo. Artículo 23. 1. Las partes en una controversia, culminado el procedimiento establecido en los artículos 4 y 5 de este Protocolo, podrán acordar expresamente someterse directamente y en única instancia al Tribunal Permanente de Revisión, en cuyo caso éste tendrá las mismas competencias que un Tribunal Arbitral Ad Hoc y regirán, en lo pertinente, los artículos 9, 12, 13, 14, 15 y 16 del presente Protocolo. 


\section{http://dx.doi.org/10.1689o/aportes.n.2.2021}

Al llegar a este punto, se observan dos cuestiones: la primera que este acceso directo no es el simple hecho de no estar conforme con una decisión y presentarse al TPR, sino que deben cumplirse ciertos pasos previos, tal y como se regula en artículo 23, ya citado, y lo es el consentimiento previo de los otros estados implicados; consentimiento que es necesario porque el asunto se someterá a una sola instancia y sus efectos serán de obligatorio cumplimiento y constituirán cosa juzgada, por lo que es necesario que los participantes en la relación procesal, ofrezcan su afirmación de someterse a este única instancia.

En caso que el Estado o los Estados no ofrezcan este consentimiento, ineludiblemente debe presentarse la reclamación por la vía ordinaria, cumpliendo los pasos previstos en el Protocolo de los Olivos, dígase negociaciones directas, GMC o TA Ad hoc, o ambos y luego TPR.

La segunda cuestión que se analiza es referida a las negociaciones directas según se regula en el artículo 4 del PO. "Los Estados partes en una controversia procurarán resolverla, ante todo, mediante negociaciones directas".

Las mismas, deben procurarse, aunque sea rechazada por los demás Estados.

La aplicación e interpretación por parte de los árbitros del Tribunal Permanente de Revisión de las normas que rigen el Mercosur sentaron sendos precedentes en el sistema de solución de controversias del Mercosur. 


\section{Análisis de la decisión del TPR a través del laudo arbitral no-1/2012}

La decisión adoptada por el TPR crea un antecedente interesante al ampliar su competencia, pues no solo conoce de los asuntos comerciales sometidos a su consideración, tal y como refleja el TA, sino también de los asuntos en materia de política que ocurran entre los Estados partes; aspecto que se considera relevante y positivo pues colma una laguna que existía el sistema del Mercosur.

Con relación al pronunciamiento sobre el acceso directo al TPR en cumplimiento con lo dispuesto en el artículo 23 del PO sobre el acuerdo expreso de las partes involucradas en la controversia emplea un razonamiento lógico, ya que el TPR actuaría como sola instancia y su laudo obligaría al cumplimiento por las partes No obstante hay que considerar que si existe un desacuerdo entre Estados, una de las partes puede negarse al acceso directo al TPR con el solo propósito de para ganar tiempo, obligando a la reclamante a transitar por todo el sistema de solución de controversias establecido.

Se analiza por tanto que esta aceptación pudiese ser tácita y no siempre expresa, abarcando dos opciones;

a) sí al presentar la demanda la aceptase y contestara el Estado demandado, o

b) no contestase la misma dentro de un plazo establecido.

En este último caso se entendería que acepta tácitamente la competencia del TPR, por lo que esté órgano daría trámite al conflicto presentado.

Según la regulación actual, si no se ofrece el consentimiento el Estado reclamado, el Estado que se considera afectado no posee otra alternativa que ir por la vía ordinaria prevista en el $\mathrm{PO}$, y si es un asunto urgente, donde no estén presentes todos los requisitos del 
Hito histórico en el Mercosur: Tribunal Permanente de Revisión y el Laudo Arbitral n 1/2012

\section{http://dx.doi.org/10.1689o/aportes.n.2.2021}

artículo 2 de la decisión $n^{\circ}$ 23/04 del Consejo del Mercado Común, implicaría riesgos para el reclamante, pues el tiempo atentaría en su contra.

Cuando al analizar el TPR los requisitos previstos en el artículo 2 de la Decisión $n^{\circ} 23 / 04$, lo interpretan como la necesaria presencia de todos para presentar una medida excepcional de urgencia, y con esta interpretación quedarían fuera de su margen de aplicación asuntos de índole económico incluso, que necesiten una solución urgente y no cumplan con ellos,

Llegado a tal punto coincidimos con lo expuesto por Deluca cuando plantea:

No obstante lo concluido precedentemente, estimamos que si bien la interpretación economicista de la procedencia del sistema de urgencia es razonable, el entendimiento del carácter acumulativo de los requisitos de admisibilidad privan de dar intervención al TPR en un sinfín de supuestos que, aun revistiendo carácter o implicancias comerciales, no podrán verse beneficiados con un pronunciamiento jurisdiccional que les otorgue mayor seguridad jurídica a los derechos de los Estados Parte o particulares involucrados como se observa en el caso analizado. ${ }^{25}$

Al analizar lo expuesto por el TPR con respecto a las negociaciones previas, alcanza la misma suerte que lo antes expuesto, pues que se hayan realizado estas o el intento de las mismas, no significa que el o los demandados ofrecerán su consentimiento para acudir directamente al TPR en única instancia.

${ }^{25}$ DELUCA, Santiago, Ob cit., p. 20. 


\section{Conclusiones}

Luego de realizar el análisis del laudo $\mathrm{n}^{\circ}$ 1/2012 dictado por el TPR se arriba a lo siguiente.

Se apreció el cumplimiento de los aspectos formales, ya que el Tribunal actuó de acuerdo a lo regulado en el PO, se constituyó, a pedido de la parte, ofreció traslado a los demandados, y resolvió dentro de los plazos estipulados.

Sobre los principales aspectos de fondo que se presentaron por Paraguay en su demanda y que fueron resueltos estuvieron relacionados con dos inconformidades; analizando en este artículo solo la relacionada con la suspensión del Estado del sistema del Mercosur.

Al realizar un análisis de la interpretación realizada por el TPR en cuanto a la aplicación del artículo 23 del PO, plantean la necesidad de una aceptación expresa para ir directamente al TPR, no dando oportunidad a la aceptación tácita, lo cual puede ocasionar daños o perjuicios a la parte interesada en resolver rápidamente el conflicto.

$\mathrm{Al}$ interpretar los árbitros del TPR los requisitos previstos en el artículo 1 de la Decisión $n^{\circ}$ 23/2004, se parte que su base histórica es plenamente comercial; no obstante, al analizarlos como integrantes de un todo, y teniendo en cuenta la constante evolución y actualización del sistema de solución de controversias del Mercosur, se dejan fuera otros asuntos mercantiles o de otra índole, política inclusive, que pudiesen necesitar una solución inmediata. 


\section{Referencias bibliográficas}

DELUCA, Santiago, "El Mercosur tras la suspensión de Paraguay y el ingreso de Venezuela: Ponderación del Laudo TPR n ${ }^{\circ}$ 1/2012", Instituto de Integración Europeo y Derecho Regional, 2013.

FORNO, Giovani, "Juicio político y debido proceso en Latinoamérica", Cuadernos Manuel Giménez, Perú, 2013. https://dialnet.unirioja.es/servlet/articulo?codigo $=434776$ o, obtenido 20 junio 2018.

ESTRAGÓ, Gloria, "Por qué es ilegal e ilegítimo el juicio político a Fernando Lugo", página web https://es.scribd.com/document/101031707/POR-QUE-ES-ILEGAL-EILEGITIMO-EL-JUICIO-POLITICO-A-FERNANDO-LUGO, obtenido 20 junio 2018.

\section{LEGISLACIÓN}

MERCOSUR. Tratado de Asunción, firmado en Asunción, República del Paraguay, el 26 de marzo de 1991.

MERCOSUR. Protocolo de Ushuaia. Sobre Compromiso Democrático en el Mercosur, la República De Bolivia y la República De Chile. Ciudad de Ushuaia, República Argentina, 24 de julio de 1998.

MERCOSUR. Protocolo de Olivos para la Solución de Controversias en el MERCOSUR, firmado en Olivos, Provincia de Buenos Aires, República Argentina, el 18 de febrero de 2002.

MERCOSUR. Consejo del Mercado Común. Decisión n 23/04. Procedimiento Para Atender Casos Excepcionales de Urgencia Art. 24 del Protocolo de Olivos para la Solución de Controversias en el Mercosur. Puerto Iguazú, 7 de julio de 2004. 
Hito histórico en el Mercosur: Tribunal Permanente de Revisión y el Laudo Arbitral n 1/2012

\section{http://dx.doi.org/10.1689o/aportes.n.2.2021}

MERCOSUR. Protocolo de Ouro Preto. Protocolo Adicional al Tratado de Asunción sobre la Estructura Institucional del Mercosur. Ciudad de Ouro Preto, República Federativa del Brasil, 17 de diciembre de 1994.

MERCOSUR. Protocolo de Brasilia para la Solución de Controversias. Ciudad de Brasilia, 17 de diciembre de 1991.

PARAGUAY. Constitución de la República Paraguay. Asunción: Diógenes, junio 2015, 133.

\section{JURISPRUDENCIA}

MERCOSUR. Decisión sobre la Suspensión de Paraguay del Mercosur 29 de julio de 2012, Mendoza, Argentina

MERCOSUR. Decisión sobre el Cese de la suspensión de Paraguay del Mercosur de fecha 12 de julio de 2013, en Montevideo, Uruguay.

TRIBUNAL PERMANENTE DE REVISIÓN. Caso Procedimiento Excepcional de Urgencia solicitado por la República del Paraguay en relación con la suspensión de su participación en los órganos del Mercado Común del Sur (Mercosur) y a la incorporación de Venezuela como miembro pleno. Laudo $n^{\circ}$ 1/2012 del 21 de julio de 2012. Disponible en: https://www.mercosur.int/documento/laudo-o12012-espanol/ 


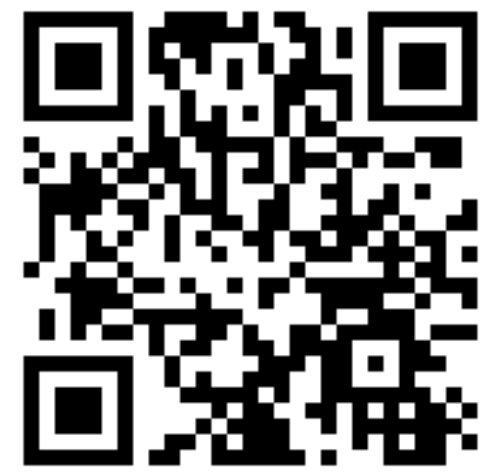

Tribunal Permanente de Revisión Avda. Mariscal López 1141 casi General Melgarejo Asunción- República del Paraguay

ISSN: 2789-2662 